\title{
Leituras de Raynal e a ilustracão na América Latina
}

\author{
Roberto Ventura
}

\section{A Fllosofia das Luzes e as Camadas Letradas Latino-Americanas}

Publicada em 1772, a Histoire des Deux Indes do Abade Raynal foi um dos maiores sucessos do mercado editorial francês no século XVIII. De 1772 a 1780 , quando aparece o texto definitivo, sāo lançadas pelo menos dezessete ediçōes integrais, além de algumas antologias. A versão de 1780 terá mais dezessete ediçőes ate 1787. Abordando a história dos impérios coloniais europeus desde a descoberta da América, a História de Raynal exerceu grande influência no Novo Mundo, chegando a vender, em versão condensada, 25 mil exemplares nos Estados Unidos ${ }^{1}$. Mas, ao contrário de outros bestsellers da época, como o Candide de Voltaire, La Nouvelle Héloise de Rousseau e a Encyclopédie de Diderot e D'Alembert, a obra de Raynal foi sendo esquecida ao longo do século XIX.

As diferentes leituras da Histoire des Deux Indes na América Latina se inserem nas condiçōes de recepção e reinterpretação dos modelos da Ilustração nas colônias portuguesas e espanholas. As "idéias francesas", como se dizia então, se difundiram entre a elite colonial, que apresentava, como marca de distinção, tanto a passagem pelo sistema de educação, quanto a pertença ou o acesso ao círculo dos funcionários, comerciantes e proprietários. As Luzes se propagaram como debate e discussão de idéias e princípios no seio das camadas letradas, excluindo a maioria da população, formada de indígenas, negros, mestiços e indivíduos sem propriedade $^{2}$.

Viajando pela América do Sul e pelo Caribe de 1799 a 1804, Humboldt observa que os criollos ou "americanos" manifestavam, sobretudo após 1789 , seu ressentimento com os privilégios concedidos pelo governo aos espanhóis. Aos criollos eram negados na América hispânica os direitos de participação na administração pública e nos postos públicos desfrutados pelos "peninsulares", criando "motivos de inveja e de raiva perpétua" entre os dois grupos ${ }^{3}$. Além dessa animosidade, $o$ interesse dos comerciantes e proprietários de terras de romper com o monopólio comercial e com os direitos fiscais da Coroa contribuiu para a difusão das idéias ilustradas.

A oralidade é a forma dominante de comunicação na sociedade ibero-americana em fins do século

1 BENOT, Y. Avertissement. In: RAYNAL, G.T. Histoire philosophique \& politique des Deux Indes. Paris, Maspero, 1981 e LUESEBRINK, H.J. Enzyklopaedismus als 'Sprache der Freiheit'. In: BADER, W. e RIESZ, J., org. Literatur und Kolonialismus I. Frankfurt/M., Bern, Peter Lang, 1983.

2 RINCÓN, C. Die Aufklaerung im spanischen Amerika. In: KRAUSS, W. Die Aufklaerung in Spanien, Portugal und Lateinamerika. Muenchen, W. Fink, 1973. p. 236.

3 HUMBOLDT, A.V. Essai politique sur le Royaume de la Nouvelle-Espagne. Paris, F. Schoell, 1811. v. 2, p. 2. 
XVIII, persistindo até o século XX. A revolução bibliográfica, trazida com a divulgação das obras de Volney, Raynal, Mably, Rousseau, Voltaire, Montesquieu, Diderot e D'Alembert, implicou um impacto considerável da cultura escrita e tipográfica em sociedades fortemente orais ${ }^{4}$. Essa revolução das formas de consciência e de representação se realizou através da mediaçāo tradutora e interpretativa dos grupos letrados, detentores da linguagem escrita.

A formação dos letrados se dava nos centros de ensino, como os colégios e universidades em Lima, México e Buenos Aires, no caso da América hispânica. No Brasil, as possibilidades de formação se encontravam restritas aos colégios secundários, controlados pelos jesuítas até sua expulsāo em 1759, limitando-se a alfabetização aos setores sociais dominantes. A ausência de faculdades no Brasil tornava necessária a permanência na Europa, em particular nas universidades de Coimbra e Montpellier, para a aquisição de educação superior. Tal fato provocou uma extrema restrição dos círculos letrados e da difusão das Luzes na colônia portuguesa. Enquanto na América hispânica 150 mil indivíduos realizaram estudos superiores até o fim da época colonial, houve, de 1772 a 1872, em um período de cem anos, 1.242 estudantes brasileiros na Universidade de Coimbra 5 .

As idéias ilustradas viajavam de

A oralidade é a forma dominante de comunicação na sociedade

ibero-americana em fins do século XVIII, persistindo até o século

$\mathbf{X X}$. navio, chegando ao Novo Mundo através das estadias de americanos na Europa, da passagem de europeus nas . colônias ou por meio da importaçăo ou contrabando de livros, opúsculos e periódicos. A Histoire des Deux Indes e outras obras centrais para a difusão dos princípios filosoficos e políticos das Luzes, como o Contrat Social de Rousseau, Des Droits et des Devoirs du Citoyen de Mably, a Encyclopédie de Diderot e D'Alembert, The History of America de Robertson, se encontram presentes em muitas bibliotecas do período colonial, apesar de sua proibição pela censura ibérica.

Em Portugal e no Brasil eram proibidos sobretudo autores franceses, como Raynal, D'Alembert, Buffon, Condorcet, Condillac, Diderot, Mably, Montesquieu, Rousseau, Voltaire, em uma lista que incluía a maior parte dos filosofos da Ilustraçăo. A censura portuguesa havia vetado ainda os Essais de Montaigne, La princesse de Clèves de Mme. de la Fayette, as Fábulas de La Fontaine, os Contes Moraux de Marmontel. Diversos livros traduzidos na língua francesa se encontravam proscritos, ou podiam ser lidos somente com licença, como obras de Pope, Swift, Sterne, Goethe, Robertson, Hume, Hobbes e Locke. The Wealth of the Nations de A. Smith e a tradução francesa de Rights of Man de Thomas Paine tamberm estavam proibidos. $O$ controle de obras, sob a responsabilidade da Inquisição, do Santo Ofício e do Rei, é unificado em 1768 pelo futuro Marquês de Pombal com a criação da Real Mesa Censória, organismo substituído em 1787 pela Comissão Geral para o Exame e a Censura dos Livros $^{6}$.

Na Espanha e na America hispânica, a História de Raynal foi proibida pela Inquisição em 1779. A

“Enciclopedia" é banida desde 1759. O Index espanhol de 1790 vetava livros de Bayle, Bossuet, Diderot, Helvétius, Holbach, La Fontaine, Marmontel, Montaigne, Montesquieu, Rousseau e Voltaire. $O$ suplemento ao

4 MOTA, C.G. Nordeste 1817. Estrutura e argumentos. Sāo Paulo, Perspectiva, 1972. p. 31.

5 CARVALHO, J.M. A construção da ordem. A elite política imperial. Rio de Janeiro, Campus, 1980. p. 21, 57-68.

6 MORAES, R.B. Livros e bibliotecas no Brasil colonial. Rio de Janeiro/São Paulo, Livros Técnicos e Científicos, Secretaria da Cultura, Ciência e Tecnologia, 1979. p. 51-7. 
Index de 1805 acrescentou à relação Condillac, Condorcet, Necker, a versão francesa de An Essay Concerning Human Understanding de Locke, e as obras de Mably e Voltaire?.

Apesar das restriçōes à venda e circulação das obras dos autores mencionados, elas se encontravam em um grande número de bibliotecas, chegando ao Novo Mundo com relativa rapidez. A Histoire des Deux Indes, cuja primeira edição data de 1772, era discutida entre os inconfidentes mineiros de 1789. Des Droits et des Devoirs du Citoyen de Mably, publicado em 1789, é objeto de interrogatórios na devassa de 1794 contra a Sociedade Literária do Rio de Janeiro. Em Portugal, o Marquês de Pombal possuía livros proibidos, como Two Treatises of Government de Locke, Les Lettres Persanes de Montesquieu, Utopia de T. Morus. $O$ Correio Brasiliense, editado em Londres por Hipólito da Costa, se encontrava interdito, sendo lido, apesar de tudo, na Corte do Rio de Janeiro, inclusive pelo Príncipe Regente. Publicaçōes proscritas, como a Enciclopédia e a História de Raynal, podiam ser consultadas na biblioteca pública de Salvador ou na do Colegio de San Marcos em Lima ${ }^{8}$.

A censura dificultava a difusão das obras colocadas no Index, mas nāo chegava a impedi-la, ainda que os infratores fossem passíveis de sanções legais. As interdiçōes despertavam possivelmente o interesse pelas leituras de obras tidas como perigosas e subversivas e os livros eram, em geral, banidos muito tempo após sua distribuição. Em uma carta de 1776 ao Marquês de Pombal, o Bispo de São
Paulo denuncia a presença de "maus" livros entre o clero da cidade, revelando os obstáculos à implantação no Brasil dos decretos da censura metropolitana:

"Escolhi o modo mais suave de lhe [ao clero] introduzir bons livros, mas não posso extinguir os maus, porque as Leis, e Editais da Real Mesa Censória, (...) ou não chegaram a esta Cidade, ou nela nāo tiveram, quem as executasse, e ficou suspenso o seu preciso efeito "9.

Os inquéritos e processos contra os participantes das inconfidências de 1789 em Minas Gerais, de 1794 no Rio de Janeiro, de 1798 na Bahia, de 1801 em Pernambuco e da insurreição de 1817 no Nordeste contêm mençōes ou inventários das obras e bibliotecas confiscadas. Uma das maiores coleções pertencia ao Cónego Luís Vieira da Silva, envolvido na conspiração de 1789 em Vila Rica. Sua biblioteca, bastante vasta para os padröes da Época, compreendia 270 obras, em um total de 800 volumes, dentre os quais se incluíam dois tomos da Encyclopédie, as Observations sur le Gouvernement des États Unis de l' Amérique de Mably, L'Esprit des lois de Montesquieu, a tradução francesa de The History of America de Robertson, livros de Voltaire, Marmontel, B. de Saint-Pierre, Condillac, Lafitau, além de diversos volumes de teologia, direito canônico e história eclesiástica. $O$ cônego possuía ainda obras representativas das Luzes ibéricas, como $O$ Verdadeiro Método de Estudar de Verney e o Teatro Crítico Universal do Padre Feijoo ${ }^{10}$.

Segundo uma testemunha, o Cônego "lia" com freqüência a Histoire de

7 HUSSEY, R.D. Traces of Enlightenment in colonial Hispanic America. In: WHITAKER, A.P., org. Latin America and the Enlightenment. New York, Cornell University Press, 1961. p. 25.

8 MORAES, op. cit., p. 57-9, 159.

9 ELLIS, M. Documentos sobre a primeira biblioteca pública oficial de Sāo Paulo. Revista de História. São Paulo, 14 (29): 387-447, 1957.

10 FRIEIRO, E. O diabo na livraria do cônego. São Paulo, Itatiaia/Edusp, 1957 e ADIM. Autos de Devassa da Inconfidência Mineira. Rio de Janeiro, Biblioteca Nacional, 1936. v. 1, p. 436; v. 5, p. 279. 


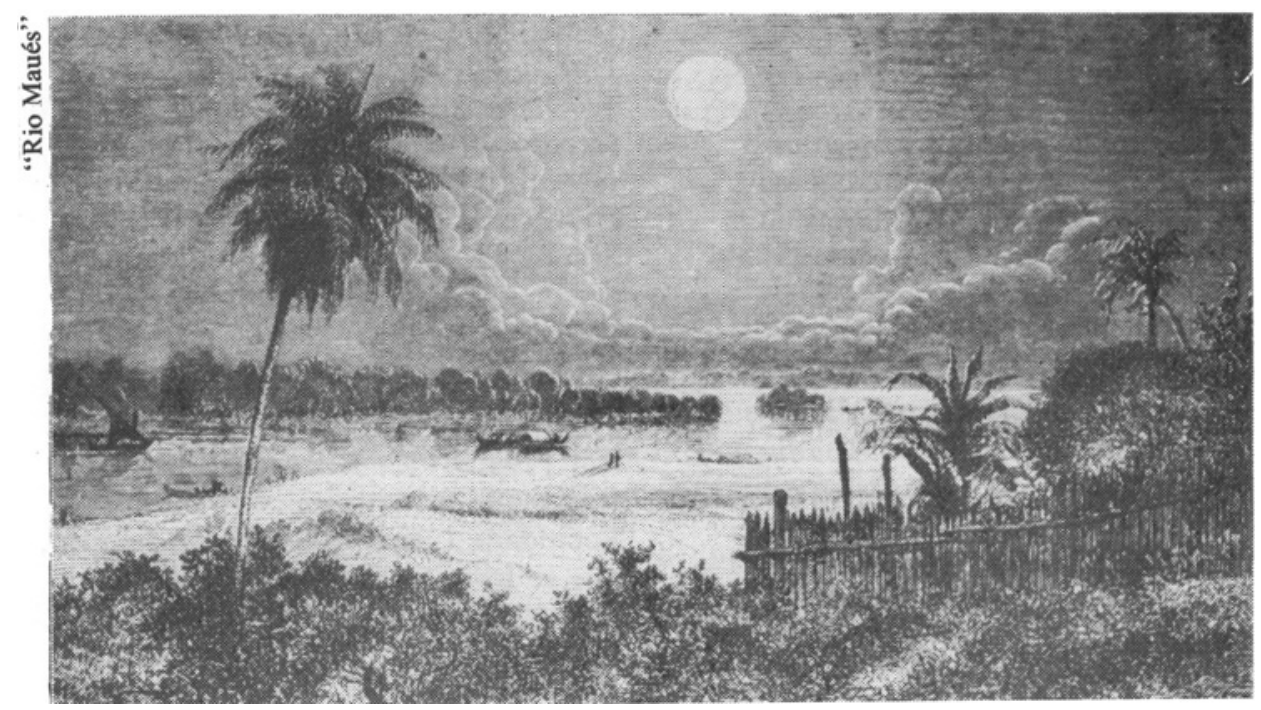

l'Amérique anglaise, provavelmente a traduçáo francesa do livro de Robertson:

"elle testemunha era amigo intimo do Conego Luis Vieira, filho destas Minas; mas que observava nelle umas tantas cousas, que se fôra Rei, the mandava cortar a cabeça, (...) sempre via empregado aquelle Conego dos successos da America Ingleza; lendo a sua Historia; a uma natural complacencia no exito, que os ditos rebeldes Americanos tiveram"11.

Outro acusado, Dr. José Pereira, possufa a História das Duas Indias e uma coleção das leis constitutivas dos Estados Unidos, que figuraram como peças de acusação no processo. A influência das idéias de Raynal é revelada por alguns depoimentos:

"ouviu dizer (...) que havia um livro de um Autor Francez, que estava na mão de um Doutor (...) o qual no fim trazia o modo de se fazerem os levantes que era cortando a cabeça ao Governador e fazendo uma fala ao Povo e repetida por um sujeito erudito, e que este livro tinha sido mandado queimar por Sua Magestade"12.

O potencial subversivo do texto de Raynal se realizaria, segundo esse testemunho, na passagem à açăo política, legitimada por uma "fala ao Povo" e ratificada por um letrado. $O$ acusado Domingos Vidal Barbosa teria divulgado as idéias do Abade com uma tal eloqüência que chegava a saber de cor algumas passagens da obra. Uma outra testemunha afirma ter ouvido dos conspiradores que:

"o Abbade Raynal tinha sido um escriptor de grandes vistas; porque prognosticou o levantamento da America Septentrional, e.que a Capitania de Minas Gerais com o lançamento do tributo da derrama estaria agora nas mesmas circumstancias"13.

A inconfidência de 1798 na Bahia, de que participam pequenos artesãos, antigos plantadores de cana e militares de baixa posiçăo, adquire um caráter mais social do que anticolonial ${ }^{14}$. A influência das idejas esclarecidas e dos modelos revolucionários

11 ADIM. Autos de Devassa da Inconfidência Mineira. Rio de Janeiro, Bibl. Nacional, 1936. v. 1, p. 110-11.

12 Ibid., v. 4, p. 180.

13 Id. ibid., p. 207.

14 MOTA, C.G. Idéia de Revolução no Brasil (1789-1801). Estudo das formas de pensamento. Petrópolis, Vozes, 1979. p. 89. 
estrangeiros ultrapassa os quadros da elite, sendo propagados slogans da Revoluçāo Francesa em manifestos que revelam a aspiração a uma sociedade igualitária, em que as diferenças raciais não representem barreiras aos cargos e à mobilidade social. Foram encontrados, com seus participantes, cadernos com transcriçōes de textos de Rousseau e uma traduçāo manuscrita da obra de Volney, com o título de Revolução dos séculos passados. Os envolvidos são acusados de fazer avançar o "Monstro da projetada Revolução" pela propagação das "imaginarias vantagens do governo da igualdade" 15 .

As Luzes comportam também um lado oficial: as novas idéias eram propagadas, em versōes amenizadas, pela administração e pela Coroa, que apoiavam a renovação científica $e$ pedagógica dos centros de ensino em Havana, Quito, Bogota, México e Buenos Aires. Na América hispânica foram fundadas sociedades, que estudavam a agricultura $e$ a mineração, publicando periódicos de orientação científica, como o Mercurio Peruano, editado de 1791 a 1795 em Lima, ou El Seminario del Reino de la Nueva Granada em Quito, a partir de 1808.

Em Portugal e no Brasil, o reformismo esclarecido se desenvolve com a administração do Marquês de Pombal, responsável pela reforma das escolas e universidades. $O$ movimento ilustrado, colocado ao serviço do absolutismo, adquire um sentido pragmático, pedagógico e científico. Esse programa modernizador leva à fundação de academias literárias e científicas, como a Academia Real das Ciências, fundada em Lisboa em 1779. No Brasil, são criadas academias literárias, dentre elas a
Sociedade Cientifica do Rio de Janeiro em 1772, que dá lugar em 1779 à Sociedade Literária do Rio de Janeiro, instalada em $1786 \mathrm{sob}$ a proteçằo do Vice-Rei ${ }^{16}$. Eram porém escassas as possibilidades de divulgação dos trabalhos das academias e sociedades brasileiras pela ausência de imprensa no período colonial, introduzida apenas com a vinda da Família Real em 1808.

Em 1794 o Vice-Rei ordena a realização de devassa contra a Sociedade Literária do Rio de Janeiro, que se torna suspeita aos "olhos" $e$ "ouvidos" da administração colonial devido à estima de seus membros pelas idéias políticas de Raynal e Mably e à sua simpatia pela inconfidência de Minas Gerais e pela Revoluçāo Francesa ${ }^{17}$. O inquérito investiga membros da sociedade, $o$ poeta e advogado Manoel Inácio da Silva Alvarenga, o licenciado em Filosofia em Coimbra. Mariano Jose Pereira, e o médico Jacinto José da Silva, formado em Montpellier.

Alvarenga possuía uma biblioteca de 1.576 volumes, com grande número de autores proibidos, como A. Smith, Fénelon, Montesquieu, Voltaire e Diderot. As autoridades o interrogam a respeito de dois volumes confiscados da História de Raynal e de uma obra de Mably:

'E logo pelo Dezembargador Chanceller foi dito a elle respondente (...) se haverem achado na sua livraria alguns tomos da Historia do Abbade Raynal livros que em muitos dos seus lugares conthem maximas e principios oppostos ás Monarchias, (...) por entre eles se encontrar o livro que tem por titolo $=$ Direitos do Cidadão $=$ do Abbade Mably livro que desde as suas primeiras linhas não tem outro objecto mais que destruir, e arruinar as
Em Portugal e no Brasil, o reformismo esclarecido se desenvolve com a administração do Marquês de Pombal, responsável pela reforma das escolas e universidades.

15 ABN. A Inconfidência da Bahia em 1798. Anais da Biblioteca Nacional. Rio de Janeiro, 1922. v. 45, p. 24.

16 MARCHANT, A. Aspects of Enlightenment in Brazil. In: WHITAKER, A.P., org. Latin America and the Enlightenment, op. cit., p. 97-113.

17 JOBIM, L. Diderot et le Brésil. In: CHOUILLET, A.M., org. Colloque International Diderot. Paris, Aux Amateurs du Livre, 1985. p. 406. 
Monarchias e estabelecer o governo Republicano"18.

$O$ acusado afirma ignorar que esses volumes contenham "doutrinas erradas, ou que se derigissem a attacar as Monarchias", acrescentando haver lido apenas os títulos, "reservando a sua lição para os tempos das ferias". Com Mariano José Pereira, a quem pertenciam os dois tomos de Raynal, foram encontrados o Emile de Rousseau e o Supplément au Voyage de Bougainville de Diderot. Segundo um depoimento, membros da Sociedade Literária aguardavam a chegada de navios da Europa com periódicos, como o Mercure de France, prontamente lidos para se colocarem a par dos progressos dos franceses na revolução. Pergunta-se a testemunha: "que liberdade tem esses caxorros dos Francezes se elles estão matando huns aos outros?"19. Após três anos de detenção, os acusados foram colocados em liberdade, sem que as autoridades confirmassem a existência de um projeto de insurreição. A libertação dos membros da Sociedade Literária fez parte de uma política de neutralização do nacionalismo, que incluía a nomeação de brasileiros diplomados pela Universidade de Coimbra, como José Bonifácio de Andrada e Silva, para cargos de importância ${ }^{20}$. $O$ inquérito mostra as limitaçōes e controles a que estavam sujeitas as academias literárias e científicas sob o reformismo esclarecido.

\section{O Homem Americano e as Civilizaçōes Antigas}

$\mathrm{Na}$ introduçăo à Histoire des Deux Indes, Raynal observa que a descoberta do Novo Mundo e a passagem para as Índias trouxeram uma revolução econômica e política, responsável pelo alargamento da visão de mundo do homem moderno:

"Começou então uma revolução no comércio, no poderio das nações, nos costumes, na indústria e no governo de todos os povos"21.

A oposição entre a Europa e a América é decisiva para a formação da consciência moderna, tornando manifesta a "superioridade" do "homem civilizado" e a possibilidade de "progresso", que tem como evidência histórica a figura do "homem selvagem" do ultramar 22 . Ao mesmo tempo, o homem americano adquire uma significação histórico-filosófica pela imagem do reino da natureza, em que a liberdade e a moral universal se realizariam através da igualdade entre os indivíduos. A interferência de dois discursos na representação do "mundo selvagem", um de apologia da felicidade natural, outro de afirmaçâo das vantagens da civilização, "indica uma visão ambígua, em que aflora a percepção de uma realidade contraditória"23.

Antonello Gerbi considera a Histoire des Deux Indes como parte da "polêmica do Novo Mundo", pela

18 ABN. Devassa ordenada pelo Vice-Rei Conde de Resende. Anais da Biblioteca Nacional. Rio de Janeiro, 1939. v. 61, p. 408-09.

19 lbid., p. 306.

20 MAXWELL, K. Conflicts and conspiracies. Brazil \& Portugal (1750-1808). Cambridge University Press, 1973.

21 RAYNAL, G.T. Histoire philosophique et politique des établissements \& du commerce des Européens dans les Deux Indes. Genève, Libraires Associés, 1775. v. 1, p. 1-2.

22 KOSELLECK, R. Kritik und Krise. Eine Studie zur Pathogenese der buergerlichen Welt. Frankfurt/M., Suhrkamp, 1959. p. 250.

23 DUCHET, M. Anthropologie et Histoire au siècle des Lumières. Buffon, Voltaire, Rousseau, Helvétius, Diderot. Paris, Maspero, 1971.p. 11. 


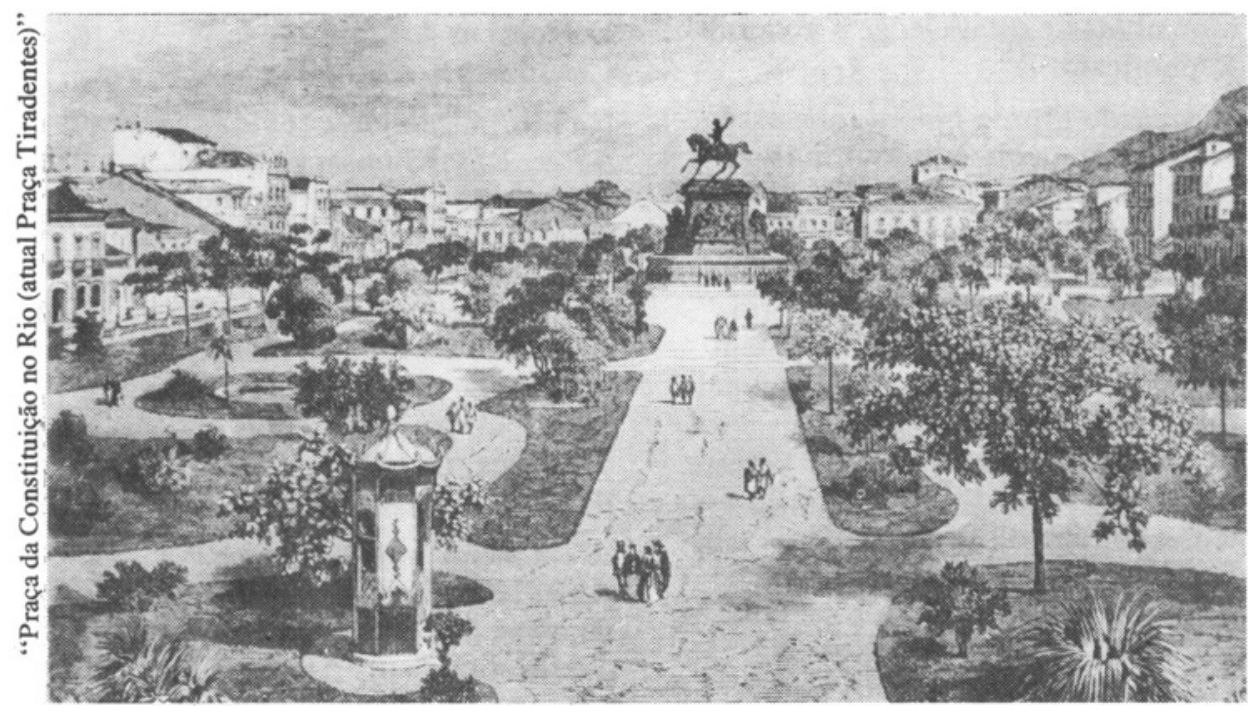

qual se difunde no pensamento da Ilustração a tese da "inferioridade" do meio americano e da "fraqueza" de suas espécies vegetais, animais e humanas $^{24}$. A filosofia das Luzes inverte a visão paradisíaca da América, formando um novo discurso sobre o homem e a natureza, marcado pela negatividade. Desse discurso fazem parte a Histoire Naturelle de Buffon, as Recherches Philosophiques sur les Américains de De Pauw, o artigo "Amérique" da Encyclopédie e a obra de Raynal. A tese sobre a inferioridade do homem e da natureza na América tem como principal antecedente a análise de Montesquieu das relações entre os climas, as instituições e os costumes, sendo a escravidão, a poligamia e o despotismo considerados formas características dos países quentes.

Raynal adota a posição de Buffon e de C. de Pauw sobre as zonas tórridas e úmidas como insalubres, atribuindo ao clima as doenças contagiosas $e$ as baixas taxas de natalidade entre os povos Guaranis do Paraguai. Mas ele não estende ao europeu ou ao criollo a tese de Buffon sobre a

"degeneração" do homem na América: os criollos teriam sofrido antes uma "degradação" de caráter, devido aos preconceitos da administração colonial contra os americanos e aos "vícios que nascem do ócio, do calor do clima, e da abundância de todas as coisas" 25.0 clima americano explicaria também a predisposição de seus habitantes ao alcoolismo e à concubinagem.

A imagem da América em Raynal resulta da projeção de uma teoria climática que divide o mapa-mundi em zonas tórridas, zonas glaciais e zonas temperadas, trazendo assimetrias valorativas com implicações políticas. Enquanto na América do Norte o clima temperado atrairia povos laboriosos e livres, favorecendo a cultura pacifica e sedentaria, na zona tórrida do continente, a escravidão e as monarquias absolutas seriam os efeitos diretos das condições naturais. A partir desse desequilíbrio climático, Raynal prevê a futura dominação pelo Norte da América do sul, "aliança monstruosa e fraca de uma raça de escravos com uma nação de tiranos"26.

24 GERBI, A. La disputa del Nuovo Mondo. Storia di una polemica. 1750-1900. Milano/Napoli, Riccardo Ricciardi, 1955.

25 RAYNAL, G.T. Histoire philosophique et ... op. cit., p. 672-73.

26 RAYNAL, G.T. Histoire philosophique \& politique des Deux Indes. Paris, Maspero, 1981. p. 227-28. 
O homem americano e as civilizaçōes antigas do México e do Peru constituem um problema epistemológico, que resiste à redução ao modelo climático adotado por Buffon, Raynal e De Pauw. Escreve Buffon na Histoire Naturelle: "O homem selvagem $\epsilon$, com efeito, de todos os animais o mais singular, $o$ menos conhecido e o mais difícil de descrever"27. Explicando pelo clima as diversidades antropológicas, Buffon atribui à expressão "Novo Mundo" uma significação geologica, ligada à pretensa formação recente da América. Esse caráter tardio do continente permitiria explicar a uniformidade do homem selvagem, apesar da existência de diversos climas: ele não se teria tornado preto nas zonas tórridas, como os habitantes da África, devido à sua menor exposição ao sol dos trópicos...

Buffon, Raynal e De Pauw contestam a antigüidade das civilizaçōes astecas, toltecas e incas, rejeitando as descriçōes de Hernan Cortés e do inca Garcilaso de la Vega, da grandeza e magnificência das cidades e monumentos. Os dados de Las Casas sobre as numerosas populaçōes do México e do Peru também são objeto de crítica, já que estes povos teriam atingido apenas recéntemente o estado social. Observa Raynal: "Deve-se relegar ao plano das fábulas esta quantidade prodigiosa de cidades construídas com tanto cuidado e dispêndio. (...) Os povos se encontravam dispersos nos campos; e era impossível que fosse de outro modo" 28 .

Em diversas obras escritas por americanos ou por europeus que habitaram na América, é discutida e colocada em questāo a idéia de uma fraqueza do homem e da natureza e da degeneração das espécies no Novo Mundo: nos escritos climáticos e geograficos do peruano Hip6lito Unánue e do padre Molina, nas Cartas Mexicanas do padre Mox6, na Historia Antigua de Mexico de Clavijero e no Ensaio Econômico sobre o Comércio de Portugal e suas Colônias de Azeredo Coutinho.

No Ensaio Econômico, Azeredo Coutinho transcreve extensas citações da obra de Raynal a respeito da "coragem" e da "imaginação ardente" dos nascidos na América. A concepção climática de Montesquieu é contestada através de uma mistura de argumentos históricos e teológicos: sua teoria das fibras nervosas faria supor, segundo Coutinho, "o absurdo que o Criador do Universo s6 soube criar fibras proprias para os climas frios ou temperados, mas não para $o$ da Zona T6rrida"29. Oriundo de uma próspera famflia de plantadores de cana-de-açúcar do Nordeste, Azeredo Coutinho foi bispo em Portugal e no Brasil, fundando o Seminario de Olinda, colégio secundário de orientação científica e experimental. Ocupou o ultimo posto de inquisidor do Reino, antés da extinção da Inquisiçāo em 1821, no mesmo ano de sua morte. Aparentemente se poderia falar de um conflito de papéis entre sua posiçăo oficial e sua atividade de ensaísta e educador, mas sua carreira é significativa da orientação pragmática das Luzes ibéricas ${ }^{30}$.

A Historia Antigua de Mexico contribuiu para a redescoberta dos monumentos americanos na segunda metade do século XVIII, o que anuncia a relativa superação da

27 BUFFON, C. de, G.L.L. Histoire naturelle. In:- Oeuvres choisies. Paris, Daguin Frères, 1749-1789. v. 3, p. 263-64.

28 RAYNAL, G.T. Histoire philosophique et politique des établissements et du commerce des Européens dans les Deux Indes. Genève, Jean-LÉnard Pellet, 1780. v. 4, p. 46.

29 COUTINHO, J.J.C.A. Ensaio econômico sobre o comércio de Portugal e suas colônias. In:- Obras econômicas. São Paulo, Cia. Ed. Nacional, 1794. p. 103.

30 BURNS, E.B. The role of Azeredo Coutinho in the Enlightenment of Brazil. The Hispanic American Historical Review. Durham, 44 (1): 145-160. Feb. 1964. 
polemica do Novo Mundo e da imagem negativa da América. Essa superação se realiza sobretudo com Alexander von Humboldt e o relato de sua viagem de exploração, a Relation historique du Voyage aux Régions équinoxiales du Nouveau Continent. Humboldt critica a tese de Buffon sobre a pretensa degeneração dos animais domésticos na América: "Essas idéias se propagaram com facilidade, porque, lisonjeando a vaidade dos europeus, se ligavam a hipóteses brilhantes sobre o antigo estado de nosso planeta"31. Refere-se ironicamente a Raynal e a De Pauw, observando a respeito dos trabalhadores indígenas e mestiços nas minas do México:

" $O$ aspecto desses homens laboriosos e robustos teria podido fazer mudar de opinião aos Raynal e aos Pauw, (...) que se comprazeram em declamar sobre a degeneração de nossa espécie na zona tórrida" 32 .

A obra de Clavijero fornece a Humboldt o ponto de partida para suas observaçóes sobre os monumentos americanos no Essai politique sur le Royaume de la Nouvelle-Espagne, sendo também mencionados os trabalhos sobre o clima de Hipólito Unánue em Lima e de Francisco Caldas em Quito, com os quais estabelece relaçōes. Humboldt se prepara para a expedição e a observação da realidade americana por um processo de leitura e estudo previo das fontes e documentos, no qual emprega seis anos, antes de partir com Bonpland em viagem que se estenderá de 1799 a 1804.

As críticas de Humboldt a Buffon, Raynal e De Pauw indicam a ruptura com a visão negativa do Novo Mundo difundida pela Ilustraçāo. Enquanto a
"História" de Raynal teve grande influência sobre os letrados latino-americanos no período de luta pela independência, os escritos de Humboldt marcarão a produçăo cultural e o pensamento político nos seculos XIX e XX, de Simon Bolívar e Jose Martí até o presente ${ }^{33}$. Os romances e ensaios de Alejo Carpentier atestam a penetração do enfoque do naturalista alemão, como em Los Pasos Perdidos, em que o seu percurso pelo Orinoco é recriado pela ficção. Em El Siglo de las Luces, o personagem Esteban revela sua desilusão com os filósofos das Luzes, após ter participado das lutas revolucionárias na Europa e na América:

"esos años (...) habían tenido el poder de envejecer tremendamente ciertas cosas: ciertos libros, sobre todo. Un encuentro con el Abate Raynal, en los entrepaños de la biblioteca, le dio ganas de reir"34.

\section{Da Rebelião de Escravos aos Direitos e Deveres do Cidadão}

A recepção da Histoire des Deux Indes nas colônias portuguesas e espanholas da América está ligada às implicaçōes políticas das posições de Raynal e de seu colaborador Diderot a respeito do tráfico de escravos, da situação dos cativos e da subordinação política às metropoles ibéricas. A independência dos Estados Unidos criou um contexto favorável à difusão da obra de Raynal na América Latina: edições com os capítulos sobre a América do Norte circulavam em versões francesas e inglesas, sob os títulos Révolution de l'Amérique (1781) e The Revolution of America (1781). Uma tradução espanhola parcial, interrompida no Livro $\mathrm{V}$, é

31 HUMBOLDT, A.V. Essai politique ... op. cit., v. 3, p. 224-25.

32 Ibid., p. 362.

33 ETTE, O. Der Blick auf die neue Welt. In: HUMBOLDT, A.V. Edição alemã da Relation historique du Voyage aux Régions équinoxiales du Nouveau Monde. Frankfurt/M., Suhrkamp, 1989 no prelo.

34 CARPENTIER, A. El siglo de las luces. Barcelona, Seix Barral, 1952. p. 261. 
publicada em Madrid de 1784 a 1790, com a supressão das partes filosóficas e dos ataques à Espanha ${ }^{35}$.

As rebelióes de escravos na colônia francesa de São Domingo e a Revolução Haitiana em 1791 dão a algumas passagens da Histoire des

Deux Indes, como o apelo ao Spartacus negro, um tom profético, gerando o temor de uma ampla revolta racial:

"Onde está esse grande homem que a natureza deve a seus filhos vexados, oprimidos, atormentados? Onde está ele? Ele aparecera, não o duvidemos, ele se mostrará, ele elevará o estandarte sagrado da liberdade. Esse sinal venerável reunirá ao seu redor os companheiros de seu infortúnio. (...) Os campos americanos se enebriarão de forma arrebatada com um sangue aguardado há tempos, e as ossadas de tantos infelizes amontoadas há três séculos tremerão de alegria"36.

Esse apelo à revolta determina a rejeição da filosofia das Luźes por Azeredo Coutinho, que defende, na Análise sobre a justiça do comércio do resgate dos escravos da Costa da Africa, o caráter humanitário do tráfico negreiro, concebido como "resgate" de indivíduos sujeitos ao cativeiro ou condenados à morte na África. Coutinho denuncia, a partir do exemplo do Haiti, as "conseqüências funestas" da transposição às colônias

Raynal afirma a existência đe três tipos de liberdade: a

liberdade natural, relativa ao homem; a

liberdade civil do cidadāo; e a liberdade política, propria a um povo. da América e das Antilhas dos

princípios dos filósofos franceses, verdadeiros "monstros" e "canibais" por seu apoio às rebeliōes de escravos.

As leituras políticas da Histoire des Deux Indes destacam os protestos contra as atrocidades coloniais, os apelos à revolta e a afirmação do princípio da liberdade e da independência, cujas passagens mais veementes foram escritas por Diderot ${ }^{37}$. Raynal afirma a existência de três tipos de liberdade: a liberdade natural, relativa ao homem; a liberdade civil do cidadão; e a liberdade política, propria a um povo Sendo a liberdade polf́tica definida como "o estado de um povo que não alienou sua soberania e que faz suas proprias leis, ou está associado, em parte, à sua legislação", os habitantes das colónias, quer escravos, quer homens livres, estāo submetidos ao cativeiro da "tirania" e do "despotismo"38.

A escravidão exprime, de forma metafórica, a subordinação política do homem tanto na Europa absolutista, quanto na América colonial, criando uma fictícia identidade de interesses entre os homens dos dois lados do Atlântico: "na Europa, como na América, os povos são escravos" 39 . Esse deslocamento metafórico já se faz presente nos artigos "Despotisme" e "Esclavage" da Encyclopédie de Diderot e D'Alembert, em que a servidão 6 associada às formas despóticas e tirânicas de governo 40 . Nos capítulos sobre a "Revolução da América", Raynal observa a ausência de contrato social entre as colônias e as metrópoles, idéia que se liga aos modos de leitura do Contrat Social de Rousseau no processo de independência da América Latina.

Simon Bolívar, de uma rica família proprietária de plantaçōes, fazendas e escravos, foi um dos principais protagonistas das lutas de independência. Criado, segundo a lenda, de acordo com o modelo do

35 TIETZ, M. Diderot und das Spanien der aufklaerung. In: HEYDENREICH, T., org. Denis Diderot. 1713-1784. Zeit - Werk - Wirkung. Erlangen, 1984. p. 142.

36 RAYNAL, G.T. Histoire des Deux Indes, op. cit., p. 202.

37 BENOT, Y. Diderot. De lathéisme à lanticolonialisme. Paris, Maspero, 1981. p. 256.

38 RAYNAL, op.cit., p. 191.

39 Id. Histoire philosophique et politique des ... Européens dans les Deux Indes. Genève, Jean-Léonard Pellet, 1780. v. 6, p. 22.

40 DIDEROT, D. e D'ALEMBERT, J.R. Encyclopédie ou Dictionnaire raisonné des sciences, des arts et des métiers. Paris, Briasson, 1754-1755. v. 4-5. 


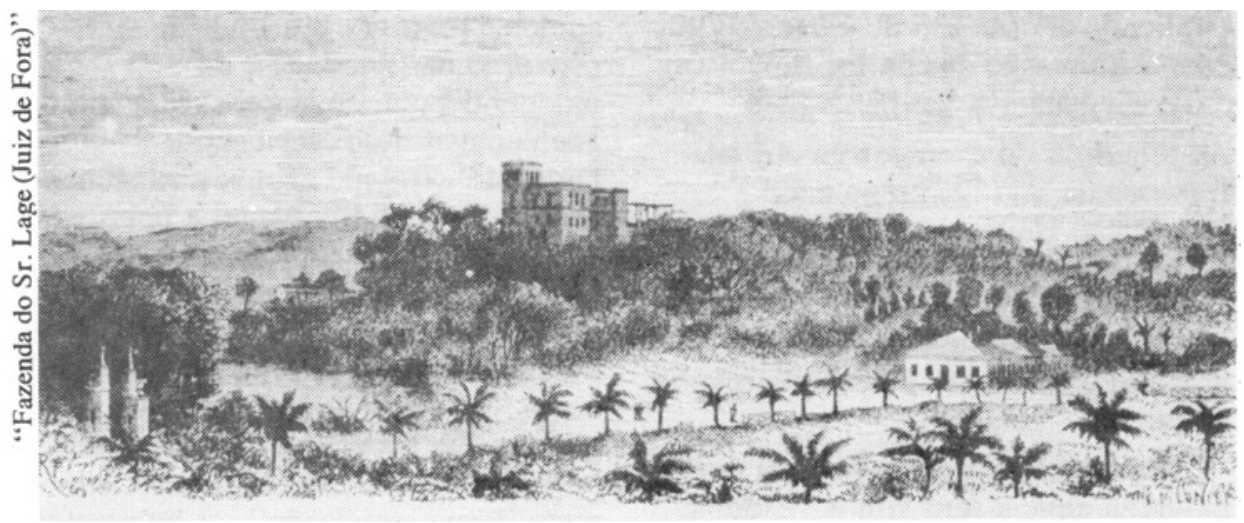

Emile de Rousseau, Bolívar realiza estudos na Espanha e passa uma longa temporada em Paris, onde assiste à coroação de Napoleão. Seu pensamento político revela os limites da filosofia das Luzes e do liberalismo nas sociedades da América Latina, a partir da tensão entre a inspiração democrática dos ideários e a orientação autocrática dos programas adotados.

Em "La Carta de Jamaica", escrita em Kingston em 1815, Bolívar proclama a inevitabilidade da ruptura política entre a América e a Europa: "el destino de la América se ha fijado irrevocablemente; el lazo que la unia a la España está cortado"41. Elogia o amor dos mexicanos por sua patria, prevendo sua próxima libertação com base no exemplo de Raynal:

"Ya ellos dicen con Raynal: llego el tiempo, en fin, de pagar a los españoles suplicios con suplicios y de ahogar esa raza de exterminadores en su sangre o en el mar"42.

Bolívar exprime o ponto de vista dos criollos, revelando a identificação entre seus interesses e os da "pátria", do "povo" e da "naçâo":

"no somos indios ni europeos, sino una especie media entre los legítimos propietarios del país y los usurpadores españoles: (...) americanos por nacimiento y nuestros derechos los de Europa"43.

A posição de Bolívar mostra o caráter problemático da identidade social das camadas criollas e dos grupos letrados latino-americanos, divididos entre a herança européia e a tradição americana. Essa ambivalência foi interpretada por Sarmiento em Facundo e por Euclides da Cunha em Os Sertóes como o resultado da luta entre as forças da civilização e as da barbárie ${ }^{44}$. Sarmiento toma Bolívar como representativo do conflito entre valores europeus e americanos, entre seu lado de Napoleão e sua faceta de caudilho. Raynal, Mably e Rousseau sâo citados como autores que contribuíram, com suas "idéias exageradas" sobre os déspotas e os tiranos, para o distanciamento político de Buenos Aires em relação aos caudilhos do interior, trazendo a anarquia, o terror $e$ a violência das guerras civis dos primordios da República Argentina ${ }^{45}$.

No discurso de abertura do Congresso de Venezuela em 1819, Bolívar

41 BOLIVAR, S. Doctrina del libertador. Caracas, Ayacucho, 1979. p. 56.

42 Ibid., p. 58.

43 Id. ibid., p. 62.

44 VENTURA, R. A nossa Vendéia: Canudos, o mito da Revoluçáo Francesa e a constituiçâo de identidade nacional-cultural no Brasil (1897-1902). Revista de crítica literaria latinoamericana. Lima, (24): 109-125, 1986.

45 SARMIENTO, D.F. Facundo: civilización y barbarie. Madrid, Alianza, 1845. p. 156, 195. 
apresenta um projeto de Constituição, proferindo sua $f^{\prime}$ nos princípios democráticos. Propõe todavia um programa político afastado do liberalismo democrático, tendo como pontos centrais o estabelecimento de Senado vitalício e hereditário, o fortalecimento dos poderes do Executivo e a divisāo entre cidadāos ativos e passivos, com base em um critério censitário. Esse desvio do liberalismo é justificado através da referência às concepçôes de Montesquieu, segundo as quais escreve Bolívar, em uma citaçāo quase literal do livro I de $L^{\prime}$ Esprit des lois - "las leyes deben ser relativas a lo físico del país, al clima, a la calidad del terreno, a su situación, a su extensión al género de vida de los pueblos" "46. Menciona ainda o caráter "heterogêneo" da população em termos étnicos e a "diferença de castas" como fatores que devem ser considerados pelo legislador ao estabelecer o sistema de governo:

"Tengamos presente que nuestro pueblo no es el europeo, ni el americano del Norte, que más bien es un compuesto de Africa y de América, que una emanación de la Europa (...). Si el principio de la igualdade politica es generalmente reconocido, no lo es menos el de la desigualdad física y moral"47.

O recurso de Bolívar à teoria do clima e às observaçōes de Montesquieu sobre a relação entre as "leis naturais" e as "leis políticas" indica a ambigüidade da concepçâo de natureza entre a elite intelectual e política das sociedades nacionais da América Latina. De um lado, a valorização da natureza local se relaciona ao projeto de fundação da pátria e de construção do Estado-nação; de outro, os grupos letrados internalizaram elementos eurocêntricos das Luzes relativos ao continente americano e ao homem selvagem e africano ${ }^{48}$. Apesar do progressivo esquecimento de Raynal no século XIX, certas estruturas ideológicas da polêmica do Novo Mundo se mantêm como elementos de explicação da distância crescente entre a América do Norte e sua contraparte latina, fazendo-se presentes no debate sobre os obstáculos à transposição dos modelos das revoluções francesa, inglesa $e$ norte-americana. Nesse sentido, as culturas nacionais latino-americanas reproduziram, de forma ambivalente, a dissimetria da imagem das duas Américas veiculada por Raynal e seus colaboradores na Histoire des Deux Indes.

\section{Bibliografia}

BURNS, E.B. The Enlightenment in two colonial Brazilian libraries. Journal of the History of Ideas. New York, 25 (3): 430-438, jul./sept. 1964.

CANECA, F. Dissertação sobre o que se deve entender por pátria do cidadão. In:Obras políticas e literárias. Recife, Tip. Mercantil, 1822. 1875-76. 2 v.

CLAVIJERO, F.J. Historia Antigua de Mexico. México, Porrua, 1780. 1982.

COUTINHO, J.J.C.A. Análise sobre a justiça do comércio do resgate dos escravos da Costa da África. In:-_ . Obras econômicas. São Paulo, Cia. Ed. Nacional, 1798. 1966.

UNÁNUE, H. Observaciones sobre el clima de Lima. In:-__. Obras cientificas y literarias. Barcelona, Tip. La Académica, 1806. 1914. v. 1. 2 v.

46 BOLf́VAR, op. cit., p. 108.

47 Id. ibid., p. 110-11.

48 VENTURA, R. Estilo tropical: a natureza como pátra. Ideologies \& literature. Minneapolis, 2 (2): 145-158, 1987.

Roberto Ventura é pesquisador do CNPq na área de teoria literária e literatura comparada na USP e integrante da área de concentração "História, Ideologias, Mentalidades" do IEA. 